\title{
Synthesis, Characterization and Mechanical Properties of Alumina-Zirconia Nanocomposite Particles
}

\author{
Ramzan Muhammad ${ }^{1}$, Bimlesh Kumar $^{2}$, Atul Chaskar ${ }^{3}$ \\ ${ }^{1}$ MMANTC, Malegaon; 3158, Lane No.1, Akbar Chawk, Dhule-424001 (M.S.) India \\ ${ }^{2}$ Department of Mechanical Engineering, Sant Gajanan College of Engineering, Kolhapur \\ ${ }^{3}$ Department of Dyestuff Technology, Institute of Chemical Technology, Matunga, Mumbai
}

\begin{abstract}
Ceramic nanocomposites have attracted a great interest of recent researchers due to its excellent attributes suitable for industrial applications such as tool engineering. In this study alumina-zirconia $\left(\mathrm{Al}_{2} \mathrm{O}_{3^{-}}\right.$ $\mathrm{ZrO}_{2}$ ) nanocomposite particles are prepared by sol-gel synthesis route and mechanical properties are determined using Halpin-Tsai approach. SEM and TEM images clearly indicate the nanosize of composite particles and dispersion of $\mathrm{ZrO}_{2}$ in $\mathrm{Al}_{2} \mathrm{O}_{3}$ matrix. The results of micrographs are in close agreement with FTIR and XRD spectra. The microstructural modification in the precursor to form the nanocomposite ceramic is suggested in the detailed discussion. A MATLAB script is written to evaluate the physical and mechanical characteristics and it is predicted that tensile strength, flexural strength and Poisson's ratio of alumina can be enhanced excellently with reinforcement of zirconia. However hardness, elastic and shear modulii can decrease proportionately.
\end{abstract}

Keywords: Alumina, Mechanical properties, Nano composites, Sol-gel methods, Transmission electron microscopy (TEM)

\section{Introduction}

During last decades, a considerable attention was focused on nanocomposites. A nanocomposite material will be formed that posses some unique properties both of the nanoparticles and the matrix where at least one of the dimensions of the filler material is of the order of a nanometer [1]. The ceramic matrix nanocomposites, which involve a uniform dispersion of nanometer size second phase particles, are a class of special materials, widely used for engineering applications [2-5]. Aluminum oxide is distinct in some properties such as high hardness, low coefficient of friction, high resistance to corrosion and thermodynamic stability $\approx \approx$ $\left.1500-1700^{\circ} \mathrm{C}\right)$ [6]. Thirunavukkarasu et al. [7] have discussed that the composite alumina - zirconia nanopowders were synthesized by sol gel process using the organometallic precursors such as aluminum secondary butoxide and zirconium n-propoxide. Zirconia $\left(\mathrm{ZrO}_{2}\right)$ which has been utilized for transformation toughening to synthesize several composites like $\mathrm{ZrO}_{2}-\mathrm{TiB}_{2}, \mathrm{WC}-\mathrm{ZrO}_{2}, \mathrm{Al}_{2} \mathrm{O}_{3}-\mathrm{ZrO}_{2}$, Mullite- $\mathrm{ZrO}_{2}, \mathrm{Si}_{3} \mathrm{~N}_{4}-\mathrm{ZrO}_{2}$, Intermetallic ( $\mathrm{Fe}-\mathrm{Al})-\mathrm{ZrO}_{2}$ etc. [8-10]. Among these composites, Zirconia Toughened Alumina (ZTA) ceramics have received a significant scientific and technological attention during the last two decades for industrial applications such as cutting tools, dye or prosthesis components because of their excellent room temperature strength, toughness and wear resistance. The lowest wear rate $\left(10^{-9} \mathrm{~mm}^{3} / \mathrm{Nm}\right)$ for ZTA against TZP (Tetragonal Zirconia Polycrystals) was reported by Kerkwijk et al.[11]. Enomoto [12] prepared $\mathrm{Al}_{2} \mathrm{O}_{3}-\mathrm{ZrO}_{2}$ composite through wet-chemical process in which $\mathrm{t}-\mathrm{ZrO}_{2}$ particles of $\sim 30 \mathrm{~nm}$ were finely dispersed within the alumina grains. ZTA ceramics were also conventionally prepared by Tang et al. $[13,14]$ through $0-15-\mathrm{vol} \% \mathrm{ZrO}_{2}$, using two processing methods: powder mixing and a modified colloidal route. Microstructure and mechanical properties of ZTA fabricated by liquid phase sintering with addition of $1 \mathrm{wt} \% \mathrm{TiO}_{2}, 1$ wt. $\% \mathrm{MnO}_{2}$ and 2 wt. \% $\mathrm{CaO}-\mathrm{Al}_{2} \mathrm{O}_{3}-\mathrm{SiO}_{2}$ (CAS) as sintering aids was studied by Huang et al. [15]. Casellas et al. [16] described the microstructure coarsening in ZTA on the basis of systems formed by second phase, which increased the fracture toughness and decreased the hardness of the synthesized material. Quintina et al. [17] have shown that the solgel processing method of ZTA results in a better control over microstructure than the powder based process and materials with good mechanical properties with a better control of porosity can be produced. Dakskobler and Kosmac [18] have prepared the alumina-zirconia composites from viscous non-polar suspensions of alumina and zirconia powders in which flexural strength increased due to the strengthening effect of the zirconia phase for layer microstructure refinement. Aruna and Rajam [19] used solution combustion synthesis and obtained less than $10 \mathrm{~nm}$ ZTA particle, which was controlled by the proper fuel ratio and the energetic of the combustion reaction. In this study zirconia toughened alumina nanocomposite particles are synthesized through sol-gel processing route. The process is found to be excellent in controlling the particle size, distribution and structural morphology illustrated by TEM and SEM images. FTIR and XRD spectra are in close agreement with micrograph results. The mechanical and physical properties of nanocomposite particles are evaluated by using 
Halpin-Tsai approach. A perspective visualization in accordance with microscopic structural modification is suggested in detailed discussion.

\section{Experimentation}

Alumina-zirconia $\left(\mathrm{Al}_{2} \mathrm{O}_{3}-\mathrm{ZrO}_{2}\right)$ nanocomposite particles were synthesized through sol-gel method with a minor modification in the protocol as reported by Sarkar et al. [20]. Hydrated $\mathrm{Al}\left(\mathrm{NO}_{3}\right)_{3} \cdot 9 \mathrm{H}_{2} \mathrm{O}$ and $\mathrm{ZrOCl}_{2} .8 \mathrm{H}_{2} \mathrm{O}$ (Both from Loba Chemie, India) were used as precursor. The requisite amounts of precursor were mixed with distilled water to achieve the solution gelation. The mixed hydrogel was obtained by adding 1:1 $\mathrm{NH}_{3}$ solution into the mixed aqueous solution maintained at ambient temperature $\left(27^{\circ} \mathrm{C}\right)$ with continuous stirring by magnetic stirrer. As $\mathrm{NH}_{3}$ solution is added dropwise the viscosity of the solution gradually increases and finally set to an enblock gel at $\mathrm{pH}$ 8.7. The gel was washed with boiling distilled water and filtered repeatedly after aging for 24 hours to remove chloride and nitrate ions. The dried gel was calcined in muffle furnace at $900^{\circ} \mathrm{C}$ in still air for 4 hours soaking time. Acetone washing was carried out to deagglomerate the nanoparticles after calcination. The complete process is illustrated by the flow chart show in Fig. 1. The SEM, TEM and FTIR are conducted at SAIF, IIT Bombay, Mumbai and XRD is carried out at UICT, NMU, Jalgaon. The TEM was Philips make, model CM200, Operating voltage 200kv and Resolution 2.4A ${ }^{\circ}$ and SEM model was JSM-7600F, accelerating voltage $30 \mathrm{kV}$ and resolution $1.0 \mathrm{~nm}$.

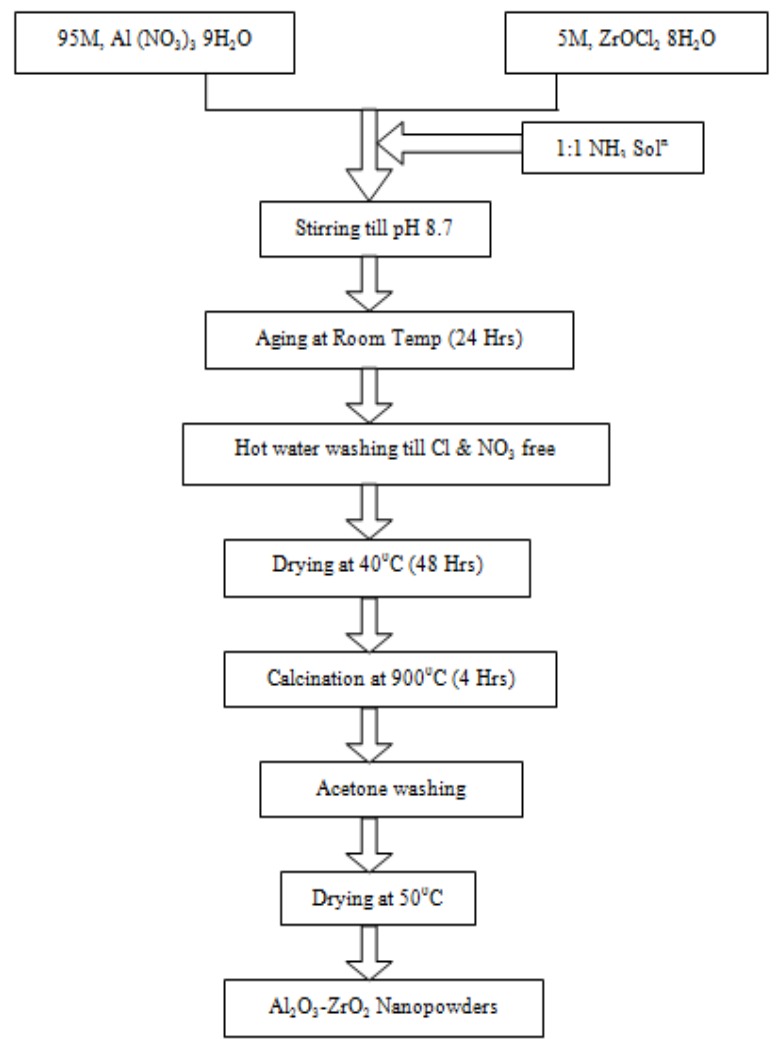

Fig. 1. Flowchart of sol-gel synthesis to prepare $\mathrm{Al}_{2} \mathrm{O}_{3}-\mathrm{ZrO}_{2}$ nanocomposite particles.

\subsection{Transmission electron microscopy (TEM)}

\section{Results And Discussion}

TEM micrographs clearly exhibit the microstructural morphology of nanocomposite and well dispersed zirconia nanoparticles in the alumina matrix. Shape of the particles is not exactly spherical due to agglomeration during calcinations at $900^{\circ} \mathrm{C}$. The dark spots inside the grey matrix indicate tetragonal-zirconia in the orthorhombic-alumina matrix which is amorphous in nature as validated also by $\mathrm{x}$-ray diffractometry and FTIR spectra. The average particle size of $\mathrm{Al}_{2} \mathrm{O}_{3}$ is $49.78 \mathrm{~nm}$ and that for reinforced $\mathrm{ZrO}_{2}$ is $5.99 \mathrm{~nm}$. The surface morphology of the nanocomposite can be observed from the micrograph shown in Fig. 2. An approximation regarding the elemental composition $\left(\mathrm{Al}_{2} \mathrm{O}_{3}-95 \%\right.$ and $\left.\mathrm{ZrO}_{2} 5 \%\right)$ of the composite can be established by observing the relative amount of grayish and dark region in the picture. Grey area shows alumina matrix whereas dark spots indicates zirconia fillers. 

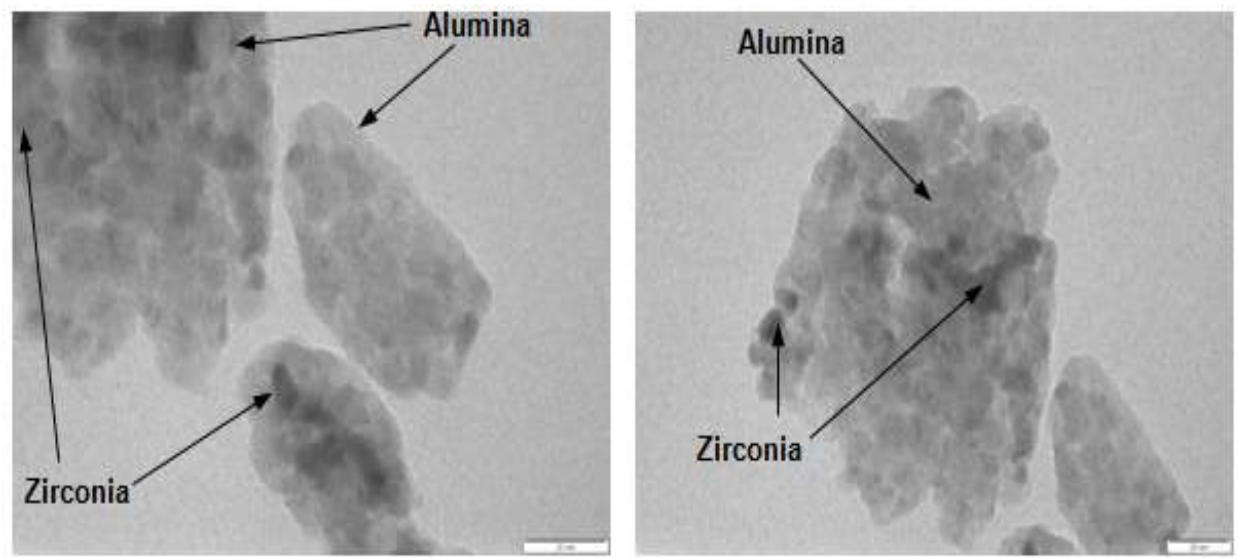

Fig. 2. TEM images of nanocomposite particles with $5 \% \mathrm{ZrO}_{2}$ in $\mathrm{Al}_{2} \mathrm{O}_{3}$ matrix

\subsection{Scanning electron microscopy (SEM)}

SEM images in Fig. 3 show the surface morphology of the nanocomposite particles. Large specific surface area and high surface energy causes clustering of some nanoparticles. The aggregation may also be occurred probably due to atmospheric moisture after the process of drying. The uniformity of the particle at nanosize is a major advantage of sol-gel synthesis process. The uniform size attributes to uniformity of the physical and mechanical properties and isotropy of the particulate.
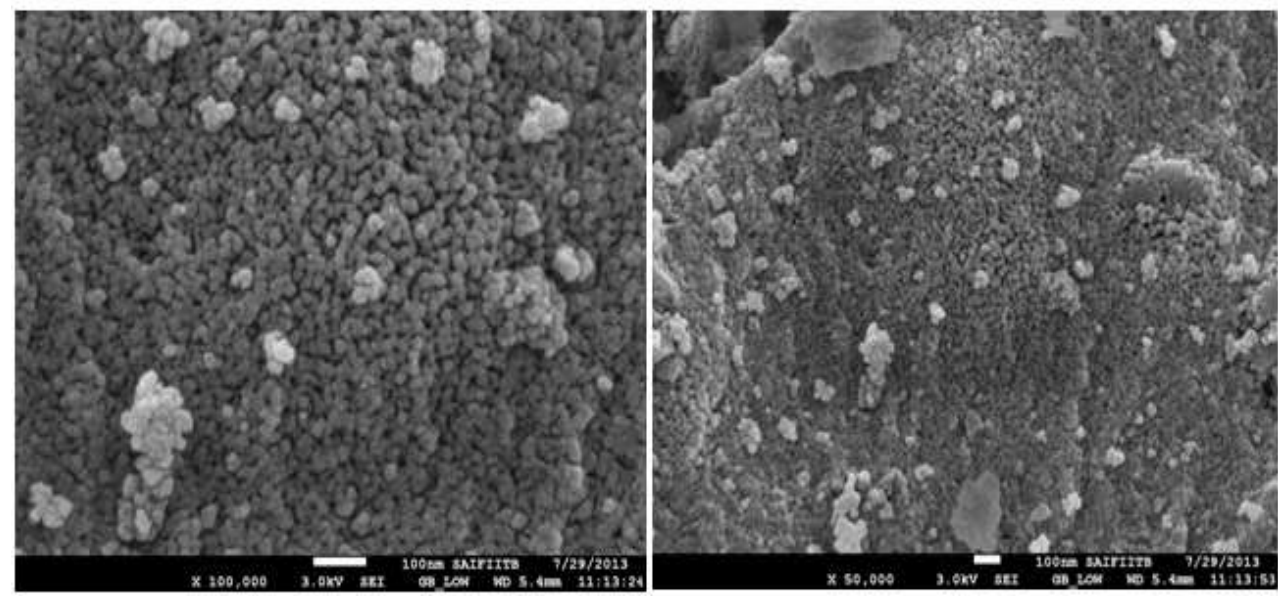

Fig. 3. SEM images of nanocomposite particles with 5\% $\mathrm{ZrO} 2$ in $\mathrm{Al} 2 \mathrm{O} 3$ matrix.

\subsection{Fourier transform infra-red spectroscopy (FTIR)}

Fig. 4 illustrates the FTIR spectrograph of the nanocomposite particles. IR Spectroscopy is an extremely effective method for determining the presence or absence of a wide variety of functional groups in a molecule. The peak at $529.67 \mathrm{~cm}^{-1}$ is the characteristic absorption of $\mathrm{ZrO}_{2}$ and the broad absorption peaks at 3439.84 and $1632.13 \mathrm{~cm}^{-1}$ can be attributed to the characteristic absorption of $\mathrm{Zr}-\mathrm{OH}$ (hydroxyls) group. The vibrations appearing in the range 4000 and $3000 \mathrm{~cm}^{-1}$ could be assigned to the coupling effect of stretching and bending vibrations of $-\mathrm{OH}$ groups. The bands at $711,821.87$ and $3786.72 \mathrm{~cm}^{-1}$ in the spectrum indicates the existence of $\mathrm{ZrO}_{2}$ (hydroxyl group) which can be ascribed to the characteristic peaks of $\mathrm{Al}-\mathrm{O}$ and $\mathrm{Zr}-\mathrm{O}$ symmetric and asymmetric stretching vibrations. The strong absorption band of the FTIR spectrum may be attributed to six-coordinated $\mathrm{Al}^{3+}$ ions. The introduction of $\mathrm{Zr}^{4+}$ increases the cationic charge in the $\mathrm{Al}_{2} \mathrm{O}_{3}-\mathrm{ZrO}_{2}$ composite which strongly interacts with the inner polar hydroxyl groups. This interaction creates an antisymmetric coupling force of attraction which probably results in the reduction of vibrational dipole moment in bending. Such results indicate that the active groups have been introduced into the matrix nanoparticle. These bands prove that $\mathrm{ZrO}_{2}$ have been chemically bonded to the nano $\mathrm{Al}_{2} \mathrm{O}_{3}$ during the sol-gel processing. FTIR spectrum also illustrates that a trace of $-\mathrm{OH}$ group always remains in the structure of $\mathrm{ZrO}_{2}$ reinforced $\mathrm{Al}_{2} \mathrm{O}_{3}$ nanocomposite even after heating at $900^{\circ} \mathrm{C}$ which could also be due to the atmospheric moisture absorption. 


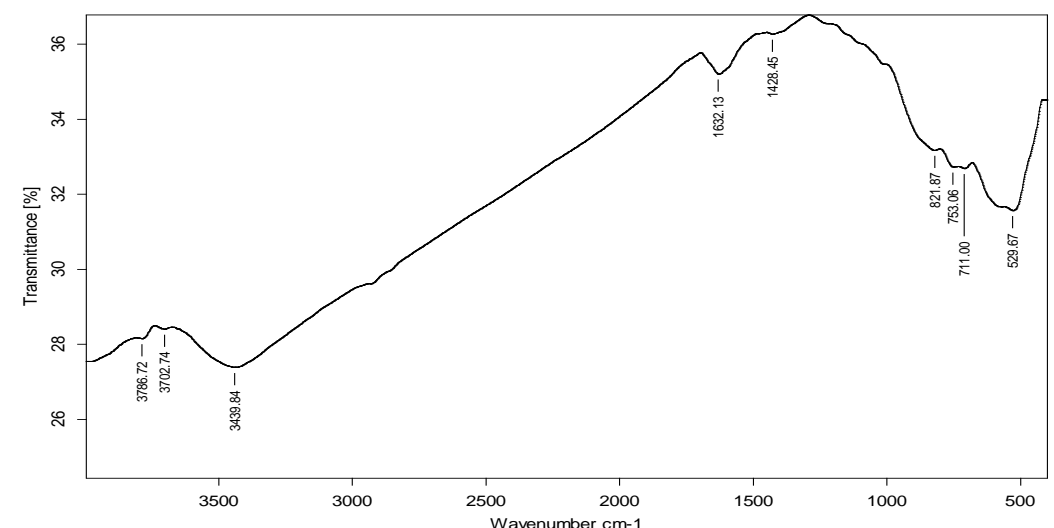

Fig. 4. FTIR spectrum of $\mathrm{Al}_{2} \mathrm{O}_{3}-\mathrm{ZrO}_{2}$ nanocomposite.

\subsection{X-ray diffractometry (XRD)}

The XRD spectrum shown in Fig. 5 reveals that the alumina belongs to $\mathrm{KAl}_{2} \mathrm{O}_{3}$ space group pna21 (33) which is most suited for wear resistance coating on cemented carbide cutting tools. A series of characteristic peaks are observed as 300, 37, 116.26, 34.6 and 59.8 in accordance with the results of the previous researchers $[21,22]$. The peaks shown in red are due to $\mathrm{ZrO}_{2}$ and that in blue reflects the appearance of ternary oxides of $\mathrm{Al}_{2} \mathrm{O}_{3}$ matrix. The additional broad and high peaks in the spectrum due to $\mathrm{ZrO}_{2}$ is widened implying that the particle size is very small according to the Debye-Scherrer formula $D=K \lambda /(\beta \cos \theta)$, where $K$ is the Scherrer constant, $\lambda$ the $\mathrm{X}$-ray wavelength, $\beta$ the peak width of half-maximum, and $\theta$ is the Bragg diffraction angle [23].

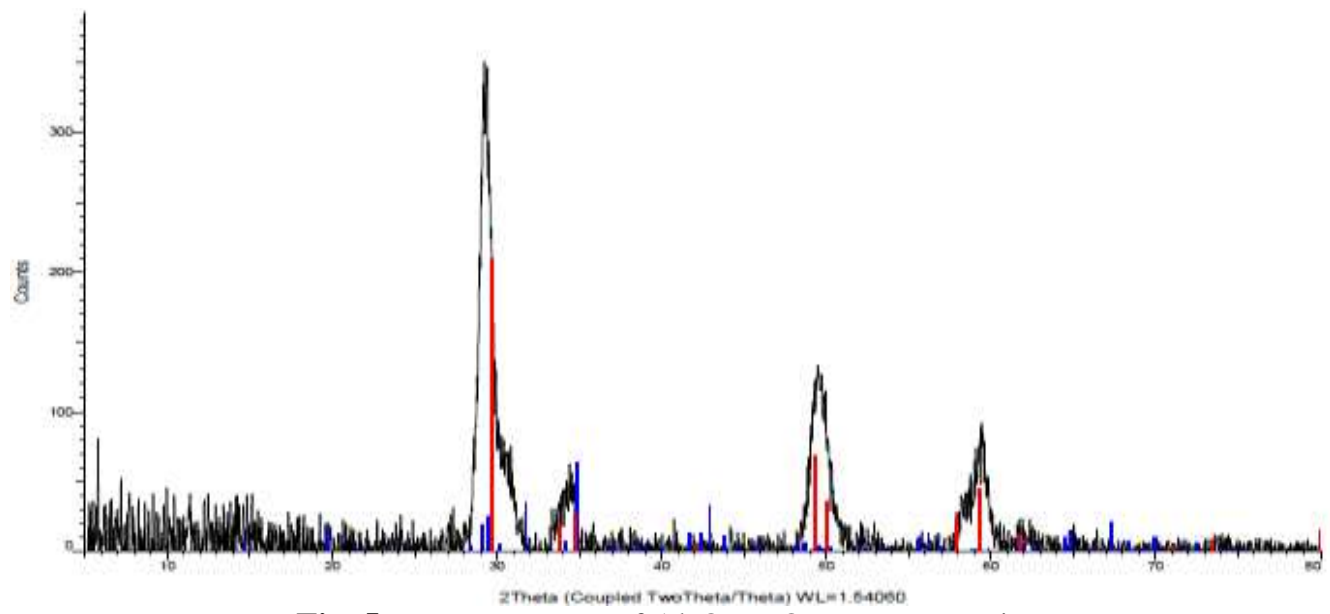

Fig. 5. XRD spectrum of $\mathrm{Al}_{2} \mathrm{O}_{3}-\mathrm{ZrO}_{2}$ nanocomposite.

Red peaks are for $\mathrm{ZrO}_{2}$ and blue peaks are for $\mathrm{Al}_{2} \mathrm{O}_{3}$. The repeated peaks in the red could be associated with the reflection of the same structure. This observation is in full agreement with TEM results revealing the composite structure of the sample which consists of nanometer scale reinforcement $(<6 \mathrm{~nm})$ in the similar size $(<50 \mathrm{~nm})$ matrix. Based on the XRD spectrum, the structure of the sample seems to be uniformly ordered, however TEM images visualize the irregular/ random shapes of the particles. Calcination at $900^{\circ} \mathrm{C}$ results in crystallization and morphology of the nanocomposite displaying numerous narrow peaks assigned to the whole set of reflection characteristics for the regular structure of $\mathrm{Al}_{2} \mathrm{O}_{3}$.

\section{Mechanical Properties}

The Halpin-Tsai equations [24, 25] use the mechanical properties of the fiber and the matrix to calculate the properties of the composite. This model assumes an isotropic particulate reinforcement of the matrix. The following relations are used to evaluate the property;

where;

$$
P=P_{m} \frac{\left(1+\varphi e_{P} v_{f}\right)}{\left(1-e v_{f}\right)}
$$

$$
e_{P}=\frac{\left(P_{f}-P_{m}\right)}{\left(P_{f}+\varphi P_{m}\right)}
$$




$$
\varphi=\left[2+\left(40 * v_{f}\right)\right]
$$

In the above Equations (1)-(3) $P$ stands for a property such as density, modulus of elasticity, Poisson's ratio etc. and suffixes $m$ and $f$ corresponds to matrix and filler respectively. The term $e_{P}$ is a factor corresponding to a property which depends on another factor $\varphi$ also varying with volume fraction of the filler. The mechanical properties of nanocomposite particles are evaluated by using the above mentioned approach. Individual characteristics of $\mathrm{Al}_{2} \mathrm{O}_{3}$ and $\mathrm{ZrO}_{2}$ are extracted from the literature and tabulated in the Table 1. The respective properties of $\mathrm{Al}_{2} \mathrm{O}_{3}-\mathrm{ZrO}_{2}$ nanoparticles reported by this study (5\% reinforcement) are illustrated in the Figs. 6-8. A MATLAB script is written to plot the trend of these characteristics with the variation in the volume fraction of nanoparticles and illustrated in the following Figs.

Table 1. Mechanical Properties of $\mathrm{Al}_{2} \mathrm{O}_{3}$ and $\mathrm{ZrO}_{2}$. The properties reported by previous researchers are taken as references [26, 27].

\begin{tabular}{|c|c|c|c|c|c|c|}
\hline \multirow[t]{2}{*}{ Sr. No. } & \multirow[t]{2}{*}{ Properties and notations used } & \multirow[t]{2}{*}{ Unit } & \multirow[t]{2}{*}{$\begin{array}{c}\text { Alumina } \\
\left(\mathrm{Al}_{2} \mathrm{O}_{3}\right)\end{array}$} & \multirow[t]{2}{*}{$\begin{array}{c}\text { Zirconia } \\
\left(\mathrm{ZrO}_{2}\right)\end{array}$} & \multicolumn{2}{|c|}{$\begin{array}{c}\left(\mathrm{Al}_{2} \mathrm{O}_{3}-\mathrm{ZrO}_{2}\right) \text { Nanocomposite } \\
(5 \% \text { by Vol. })\end{array}$} \\
\hline & & & & & By this study & From Literature \\
\hline 1 & Density $(\rho)$ & $\mathrm{Kg} / \mathrm{m}^{3}$ & 3900 & 6000 & 3995.23 & 4100 \\
\hline 2 & Tensile Strength $\left(\sigma_{\mathrm{T}}\right)$ & $\mathrm{MPa}$ & 480 & 1100 & 504.85 & ---- \\
\hline 3 & Hardness (Vickers) & VPN & 2000 & 1300 & 1962.64 & 1750 \\
\hline 4 & Flexural Strength & $\mathrm{MPa}$ & 379 & 900 & 399.69 & 760 \\
\hline 5 & Elastic Modulus (E) & $\mathrm{GPa}$ & 370 & 205 & 361 & 310 \\
\hline 6 & Shear Modulus $(\mathrm{G})$ & GPa & 152 & 80 & 148.03 & $\begin{array}{ll}--- \\
\end{array}$ \\
\hline 7 & Thermal Conductivity $(\lambda)$ & $\mathrm{W} / \mathrm{mK}$ & 35 & 2 & 33 & 23 \\
\hline 8 & Fracture Toughness & $\mathrm{MPa}^{\mathrm{m}} \mathrm{m}^{1 / 2}$ & 4 & 13 & 4.31 & 6 \\
\hline 9 & Poisson's Ratio $(v)$ & No unit & 0.22 & 0.31 & 0.224 & 0.23 \\
\hline
\end{tabular}

The microstructure of ZTA consists of alumina matrix containing dispersed particles of zirconia. The mechanical properties of nanocomposite can be significantly improved via two different mechanisms: microcracking and stress induced transformation toughening. Microcracks are induced by the volume change of $\mathrm{ZrO}_{2}$ phase during sintering and calcination, when cooled through the transformation temperature. Tangential stresses are generated around the transformed particle that induces microcracks in the matrix. The cracks have the ability to absorb or dissipate the energy, thereby increasing the toughness of the composite. Stress-induced transformation toughening is caused by tetragonal zirconia particles when interacting with an advancing crack which then promote a toughening effect through the permanent dilatation and reduced modulus that they imply around the crack-tip. Since the strain occurs in the vicinity of the crack; extra work would be required to move the crack through the ceramic, accounting for the increase in toughness and strength [28, 29]. The hardness of the ZTA composite decreases as alumina is harder than zirconia. The difference in the coefficient of thermal expansion between the matrix and the dispersed phases causes the reduction in thermal conductivity of the composite. The modulus of elasticity of the composite depends on the volume fraction of the phases present and their individual modulii. Elastic modulus of alumina is greater than that of zirconia, hence the addition of zirconia affects adversely on modulus of the composite.

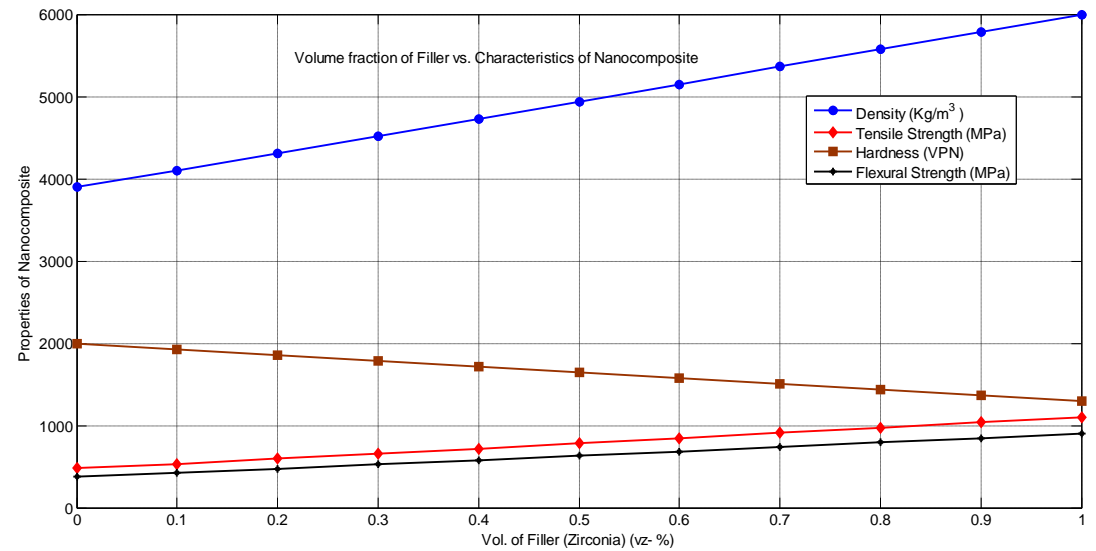

Fig. 6. Mechanical Properties of $\mathrm{Al}_{2} \mathrm{O}_{3}-\mathrm{ZrO}_{2}$ nanocomposite. Density, Tensile Strength and Flexural Strength increases, whereas Hardness decreases. 


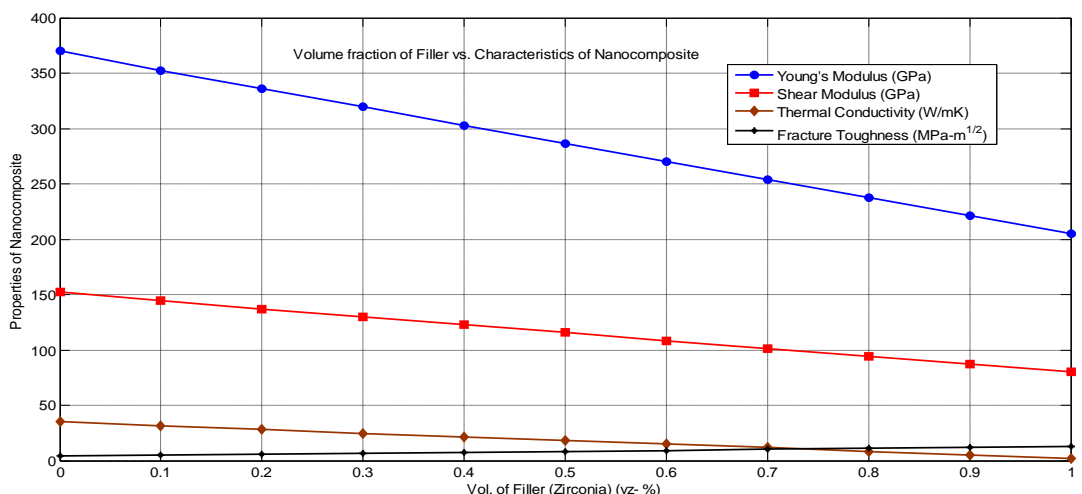

Fig. 7. Mechanical Properties of $\mathrm{Al}_{2} \mathrm{O}_{3}-\mathrm{ZrO}_{2}$ nanocomposite. Fracture Toughness increases, whereas Modulii and Thermal Conductivity decreases.

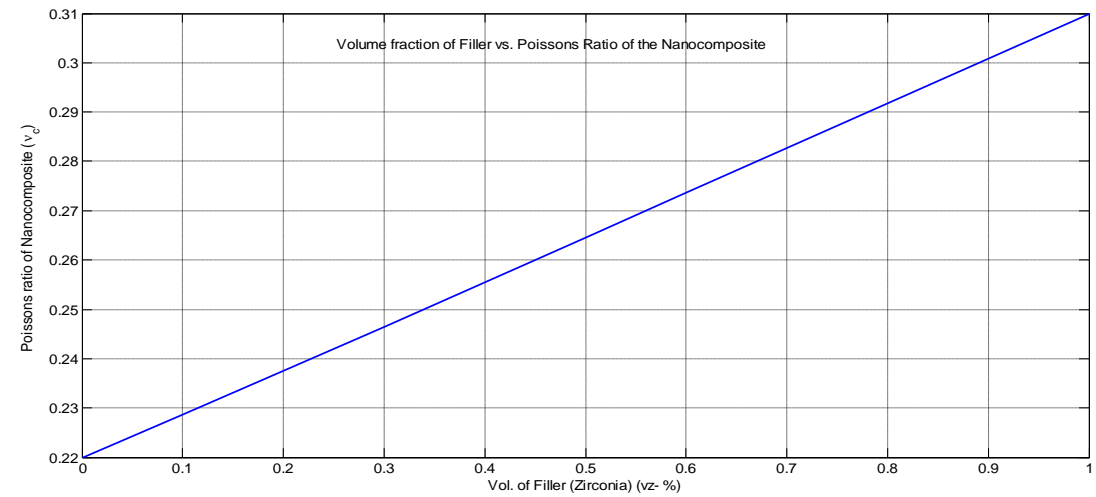

Fig. 8. Mechanical Properties of $\mathrm{Al}_{2} \mathrm{O}_{3}-\mathrm{ZrO}_{2}$ nanocomposite. Poisson's Ratio directly increases with increase in volume fraction of nanofillers.

\section{Microsystem Interaction}

The results of this study provide a clear evidence for the complexity of the structural genesis of binary $\mathrm{ZrO}_{2}$ into ternary $\mathrm{Al}_{2} \mathrm{O}_{3}$ oxides. It exists from an amorphous solid precursor $\left(\mathrm{Al}\left(\mathrm{NO}_{3}\right)_{3}\right.$ and $\left.\mathrm{ZrOCl}_{2}\right)$ through assembling of nanosized crystallites during sol-gel processing up to a final well-crystalline compound. Interestingly, a remarkable point is that the transformation of the chloride and nitrous precursor from a nanostructural state into a regular nanocomposite structure occurs in a fairly narrow temperature interval at ambient temperature. The nanocomposite structure described as a network built up of tetragonal $\mathrm{ZrO}_{2}$ with lattice parameters $\mathrm{a}=\mathrm{b}=7.28818 \AA, c=5.30143 \AA$ and $\alpha=\beta=\gamma=90^{\circ}$ in orthorhombic $\mathrm{Al}_{2} \mathrm{O}_{3}$ matrix with lattice parameters $\mathrm{a}=4.84350 \AA, \mathrm{b}=8.22240 \AA, \mathrm{c}=9.00110 \AA$. Though the structure of the complex $\mathrm{Al}_{2} \mathrm{O}_{3}-\mathrm{ZrO}_{2}$ compound has not been determined yet, this study may provide some suggestions concerning the distribution of the $\mathrm{Zr}$ doping ions in the $\mathrm{Al}$-oxide structure. $\mathrm{Zr}^{4+}$ ions have been found in octahedral coordination characteristic for $\mathrm{Al}^{3+}$ ions. Since the structure of $\mathrm{Al}_{2} \mathrm{O}_{3}-\mathrm{ZrO}_{2}$ is based on slabs of octahedrons occupied by $\mathrm{Al}^{3+}$ ions, these positions might be, therefore, partially occupied by $\mathrm{Zr}^{4+}$ ions. The lateral growth of $\mathrm{ZrO}_{2}$ slabs inside the $\mathrm{Al}_{2} \mathrm{O}_{3}$ is controlled by diffusional migration of the $\mathrm{O}^{2-}$ ions. The nucleation and growth of triclinic $\mathrm{ZrO}_{2}$ cell is controlled by the rapid and diffusionless shear displacement of the $\mathrm{Zr}^{4+}$ ions. The orientation of the $\mathrm{Zr}^{4+}$ and $\mathrm{O}^{2-}$ ions to their respective positions are controlled by the diffusional displacement of the respective ions, transformation temperature and time [27]. At the same time, FTIR spectrum delivers certain hints on the presence of $\mathrm{Zr}^{4+}$ ions in an uncommon, maybe highly distorted trigonal pyramidal coordination. We may speculate that these ions substitute $\mathrm{Al}^{3+}$ ions in orthorhombic bipyramidal sites. It is to be noted that the analogies exist in the preferred coordination of $\mathrm{Al}^{3+}$ and $\mathrm{Zr}^{4+}$ ions.

\section{Conclusion}

Sol-gel process is found to be an effective route to form alumina-zirconia nanocomposite particles with control over size, distribution and morphology of the compound. TEM and SEM micrographs verify the microstructural details, nanometer size and reinforced features of secondary phase in the ceramic matrix which is also validated by IR spectroscopy and X-ray Diffractometry. The physical and mechanical properties of the composite are found to be a function of dispersed zirconia particle size and could be mentioned as below:

1. Hardness decreases with the addition of zirconia as alumina is much harder than zirconia.

2. Tensile strength and flexural strength increases linearly with volume fraction of zirconia. 
3. The fracture toughness also increases due to microcrack formation at the orientation of zirconia particles, but the stiffness decreases reducing the elastic and shear modulii.

4. Density and Poisson's ratio are in direct proportion with volume fraction of zirconia.

\section{Acknowledgement}

The authors gratefully acknowledge the instrumentation facility provided by SAIF, IIT Bombay, Mumbai for SEM, TEM and FTIR and UICT NMU, Jalgaon for XRD. There is no specific grant from any funding agency in the public, commercial, or not-for-profit sectors.

\section{References}

[1]. H. Farzana, H. Mehdi, and O. Masami et al. Review article: Polymer-matrix nanocomposites, processing, manufacturing, and application: An overview, Journal of Composite Materials, 40(17), 2006, 1511-1575

[2]. K. Niihara, New design concept of structural ceramics-ceramic nanocomposite, Journal of Ceramic Society of Japan, 99(10), 1991, 974-982.

[3]. S. Komarneni, Nanocomposites, Journal of Materials Chemistry, 2(12), 1992, 1219-1230.

[4]. A. Borrell, V.G. Rocha, and R. Torrecillas et al. Effect of carbon nanofibers content on thermal properties of ceramic nanocomposites, Journal of Composite Materials, 46(10), 2012, 1229-1234.

[5]. K.S. Tun, and M. Gupta, Role of Microstructure and Texture on Compressive Strength Improvement of $\mathrm{Mg} /\left(\mathrm{Y}_{2} \mathrm{O}{ }_{3}+\mathrm{Cu}\right) \mathrm{Hybrid}$ Nanocomposites, Journal of Composite Materials, 44(25), 2010, 3033-3050.

[6]. E. Dorre and H. Hubner, Alumina (New York: Springer-Verlag, 1984).

[7]. A. Thirunavukkarasu, S.K. Malhotra, and S. Paramanand, High Toughness Alumina - Zirconia Nanocomposites from Sol gel Nanopowders, Int Symp of Research Students on Material Science and Engineering, Chennai, India, 2004, 1-9.

[8]. B. Basu, T. Venkateswaran, D. Sarkar, Pressureless sintering and tribological properties of WC-ZrO2 composites. Journal of European Ceramic Society, 25 (9), 2005, 1603-1610.

[9]. R.H.J. Hannink, and M.V. Swain, Progress in transformation toughening of ceramics, Annual Review of Material Science, 24, 1994, 359-408.

[10]. S. Kobayashi, and S. Wada, Strengthening of $\mathrm{Si}_{3} \mathrm{~N}_{4}$ Ceramics by $\mathrm{ZrO}_{2}$ additions, Advances In Ceramics, 24A, 1998, $127-132$.

[11]. B. Kerkwijk, A.J.A. Winnubst, and H. Verweij et al. Tribological properties of nanoscale alumina-zirconia composites, Wear, 225, 1999, 1293-1302.

[12]. J.M. Tang, M. Uehara, and H. Maeda et al. Process study on alumina-zirconia nanocomposite via ammonolysis route, Journal of Ceramic Processing and Research, 1(2), 2000, 88-91.

[13]. R. Guo, D. Guo, and D. Zhao et al. Low temperature ageing in water vapor and mechanical properties of ZTA ceramics, Materials Letters, 56, 2002, 1014-1018.

[14]. H. Antonio, D. Aza, and J. Chevalier et al. Slow-crack- growth behavior of Zirconia-toughened Alumina ceramics processed by different methods, Journal of American Ceramic Society, 86 (1), 2003, 115-120.

[15]. X.W. Huang, S.W. Wang, and X.X. Huang, Microstructure and mechanical properties of ZTA fabricated by liquid phase sintering, Ceramics International, 29, 2003, 765-769.

[16]. D. Casellas, M.M. Nagl, and L. Llanes et al. Fracture toughness of alumina and ZTA ceramics: microstructural coarsening effects, Journal of Materials Processing Technology, 143-144, 2003, 148-152.

[17]. A.P. Quintina, M.H. Bergera, and A.R. Bunsella et al. Processing and structures of bi-phase oxide ceramic filaments, Journal of European Ceramic Society, 24, 2004, 101-110.

[18]. A. Dakskobler, and T. Kosmac, The preparation and properties of $\mathrm{Al}_{2} \mathrm{O}_{3}-\mathrm{ZrO}_{2}$ composites with corrugated microstructures, Journal of European Ceramic Society, 24, 2004, 3351-3357.

[19]. S.T. Aruna, and K.S. Rajam, Mixture of fuels approach for the solution combustion synthesis of $\mathrm{Al}_{2} \mathrm{O}_{3}-\mathrm{ZrO}_{2} \mathrm{nanocomposite}$ Materials Research Bulletin, 39, 2004, 157-167.

[20]. D. Sarkar, S. Adak, and N.K. Mitra, Preparation and characterization of an $\mathrm{Al}_{2} \mathrm{O}_{3}-\mathrm{ZrO}_{2}$ nanocomposite, Part I: Powder synthesis and transformation behavior during fracture, Composites A: Applied Science and Manufacturing, 38(1), $2007,124-131$.

[21]. S.J. Mousavi, S.M. Hosseini, and M.R. Abolhassani et al. Calculation of the structural, electrical, and optical properties of $\mathrm{K}_{-} \mathrm{Al}_{2} \mathrm{O}_{3}$ by density functional theory, Chinese Journal of Physics, 46(2), 2008, 170-180.

[22]. M. Yashima, Crystal structures of the tetragonal Ceria- Zirconia solid solutions Ce x Zr1- x O2 through first principles calculations $(0 \leq x \leq 1)$, Journal of Physical Chemistry C, 113(29), 2009, 12658-12662.

[23]. R.Y. Hong, J.H. Li, and L.L. Chen LL et al. Synthesis, surface modification and photocatalytic property of ZnO nanoparticles, Powder Technology, 189, 2009, 426-432.

[24]. J.E. Ashton, J.C. Halpin, and P.H. Petit, Primer on composite materials: Analysis. (Stamford: Technomic Pub., 1969).

[25]. J.C. Halpin, Stiffness and expansion estimates for oriented short fiber composites. Journal of Composite Materials, 3, 1969, 732734.

[26]. http://accuratus.com/zirc.html (Accessed on 03 Sept, 2013 at 04:16 p.m. IST.)

[27]. D. Sarkar, Synthesis and thermo-mechanical properties of sol-gel derived Zirconia toughened Alumina nanocomposite, doctoral diss., NIT Rourkela, India, 2007.

[28]. F.F. Lange, B.I. Davies, and D.O. Raleigh, Transformation strengthening of $\beta^{\prime \prime}-\mathrm{Al}_{2} \mathrm{O}_{3}$ with tetragonal $\mathrm{ZrO}$. Journal of American Ceramic Society, 66 C, 1983, 125-127.

[29]. R. Stevens, Zirconia and Zirconia Ceramics, (Magnesium Elektron, 1986). 